\title{
Silibinin: an old drug for hematological disorders
}

Review

\author{
Hai Zou ${ }^{1,6}$, Xing-Xing Zhu ${ }^{2,6}$, Guo-Bing Zhang ${ }^{3,6}$, Yuan Ma ${ }^{1,6}$, Yi Wu ${ }^{4,6}$ and Dong- \\ Sheng Huang ${ }^{5,6}$ \\ 1'Department of Cardiology, Zhejiang Provincial People's Hospital, Hangzhou 310000, China \\ ${ }^{2}$ Department of Nephrology, Zhejiang Provincial People's Hospital, Hangzhou 310000, China \\ ${ }^{3}$ Department of Pharmacy, Zhejiang Provincial People's Hospital, Hangzhou 310000, China \\ ${ }^{4}$ Department of Hematology, Zhejiang Provincial People's Hospital, Hangzhou 310000, China \\ ${ }^{5}$ Department of Hepatobiliary Surgery, Zhejiang Provincial People's Hospital, Hangzhou 310000, China \\ ${ }^{6}$ People's Hospital of Hangzhou Medical College, Hangzhou 310000, China
}

Correspondence to: Yi Wu, email: wuyi@zjheart.com

Dong-Sheng Huang, email: dshuang@zju.edu.cn

Keywords: silibinin, $\beta$-thalassemia, acute myeloid leukemia, anaplastic large cell lymphoma, multiple myelomas

Received: February 28, $2017 \quad$ Accepted: June 27, $2017 \quad$ Published: July 11, 2017

Copyright: Zou et al. This is an open-access article distributed under the terms of the Creative Commons Attribution License 3.0 (CC BY 3.0), which permits unrestricted use, distribution, and reproduction in any medium, provided the original author and source are credited.

\section{ABSTRACT}

Introduction: Silibinin (silybin), a non-toxic natural polyphenolic flavonoid, is the principal and the most biologically active component of silymarin. It is efficient in the treatment of acute and chronic liver disorders caused by toxins, drug, alcohol, hepatitis, and gall bladder disorders. Further, in our previous studies, we explored the anti-cancer efficacy in common cancers, such as lung, prostatic, colon, breast, bladder, as well as, hepatocellular carcinoma. Interestingly, silibinin is still not solely limited to the treatment of these diseases. Recent research endeavors suggest that silibinin may function diversely and serve as a novel therapy for hematological disorders.

Areas covered: It discovered several interesting viewpoints in the widely studied mechanisms of silibinin in the hematological disorders.

Expert commentary: In this report, we review the up-to-date findings of more potency roles of silibinin in $\beta$-thalassemia $(\beta-T M)$, acute myeloid leukemia (AML), anaplastic large cell lymphoma (ALCL) and multiple myelomas (MM) therapy and attempt to clarify the mechanisms underlying its effects. There are two viewpoints: First, The functional mechanisms of silibinin in AML cells via regulating cell differentiation to exert anti-cancer effect; Second, combination treatment strategy may be a good choice.

\section{INTRODUCTION}

Silibinin (silybin) (Figure 1), is a non-toxic natural polyphenolic flavonoid and the main biologically active component of silymarin. It is efficacious in the treatment of acute and chronic liver disorders caused by toxins, drug, alcohol and hepatitis and gall bladder disorders. Additionally, silibinin has been shown to exert anti-cancer efficacy in well-known cancers, such as lung cancer, prostatic cancer, colon cancer, breast cancer, bladder cancer and also, in hepatocellular carcinoma [1,2]. In this review we assessed other aspects of silymarin therapeutic potential and summarized the findings regarding the role of the drug in hematological disorders, such as $\beta$-thalassemia $(\beta-T M)$, acute myeloid leukemia (AML), anaplastic large cell lymphoma (ALCL) and multiple myelomas (MM).

\section{$\beta$-thalassemia}

$\beta$-thalassemia $(\beta-\mathrm{TM})$ is a chronic hereditary disease, which is characterized by ineffective RBC synthesis due to unbalanced hemoglobin chains production, with the highest prevalence in the Mediterranean Region [3]. Severe chronic anemia, hepatosplenomegaly (SCAH), jaundice, gallstones and bone deformities often develop in homozygous $\beta$-TM patients. Although regular blood 
transfusion could be an effective treatment and reduces mortality, iron overload and oxidative stress have been implicated as the principal precipitating factors of immune deficiency in $\beta$-TM major $[4,5]$. Furthermore, oxidative stress, inflammation, hepatic involvements, osteoporosis, and cardiac and renal insufficiency are major causes of iron overload related morbidity in patients with $\beta$-TM [6]. Studies have demonstrated that reactive oxygen intermediates, such as superoxide anion $\left(\mathrm{O}_{2}\right)$, hydroxyl radicals $(\mathrm{OH})$ and hydrogen peroxide $\left(\mathrm{H}_{2} \mathrm{O}_{2}\right)$, are in excess in the TM erythrocytes. The reason for this elevation is because of the inhibition of exogenous antioxidant capacity, in particular, vitamin E and zinc in $\beta$-TM $[7,8]$. Recently, a series of studies reported that silibinin exerts the property of iron-chelating in patients with $\beta$-TM major $[9,10]$. For inflammation, a study showed that a significantly higher concentration of TGF- $\beta$ and IL-23 in the $\beta$-TM group than control group, and compared with IL-10 values at baseline, there is a significant reduction in serum IL-10 levels in $\beta$-TM patients treated with silibinin. These data suggested that silibinin could be a promising drug for restoring immune response defects in $\beta$-TM therapy [11]. A further study indicated that silibinin stimulated a cell-mediated immune response in a $\beta$-TM major, possibly through a direct effect on cytokineproducing mononuclear cells, and an indirect action in reducing ferritin and free radical generation during iron-chelating treatment [3]. A recent study showed that silibinin in combination with oral deferasirox (Exjade) could be used safely in the treatment of iron-loaded TM patients as it showed good iron chelation with no sign of toxicity [12]. Moayedi et al. suggested that silibinin was effective at reducing iron overload in patients when used in conjunction with desferrioxamine [10]. It suggests that silibinin possesses the potential effectiveness of silibinin alone in reducing body iron burden [10]. Pieces of evidence have, however, suggested that silibinin could protect $\beta$-TM, and considered the likelihood of iron chelation effect with a favorable safety profile. There is the need to conduct more clinical research to evaluate the efficacy of silibinin in $\beta$-TM treatment. Hopefully, it will improve the life expectancy of patients with this debilitating illness.

\section{ACUTE MYELOID LEUKEMIA}

Acute myeloid leukemia (AML), a clonal disorder of hematopoietic stem cells, was characterized by an increase in the number of myeloid cells in the marrow and an arrest in their maturation [13]. Dates showed that the incidence of AML ranges from three to five cases per 100,000 population in the United States. Over 10,000 patients died from this disease in 2015 alone [14]. The majority of patients presents with a combination of leukocytosis, anemia, and thrombocytopenia. Subsequently, fatigue, anorexia, and weight loss are common complaints. If patients' did not accept effective treatment, death usually ensues within months of diagnosis secondary to infection or bleeding [15]. The backbone of therapy of AML has been a combination of cytarabine- and anthracyclinebased regimens, and allogeneic stem cell transplantation for eligible candidates [15]. AML is a type of malignancy that is lacking in effective treatment for most patients. The development of new therapies, in concert with proper control of signaling checkpoints in upregulated pathways, as well as, improved genetic profiling, are expected to offer novel and promising methods for AML therapy. Comprehensive studies have demonstrated that silibinin is a novel and promising anticancer agent in AML [16, 17]. Experimental evidence showed that silibinin was capable of markedly suppressing cell growth and produced an anti-proliferative effect, which led to a massive apoptotic cell death in HL-60 and KG-1a human AML cells. Also, time- and dose-dependent cytotoxicity did not substantially accompany these effects [16]. Silibinin exerts an anti-cancer effect based on the by-pass of the block to differentiation caused by the mutations and or epigenetic change in AML cells. What is more, silibinin has been described as phytochemical which could enhance 1,25-dihydroxyvitamin D3 (1,25D), a potent differentiation inducer which has a potential for the treatment of AML- [18] induced differentiation of HL60

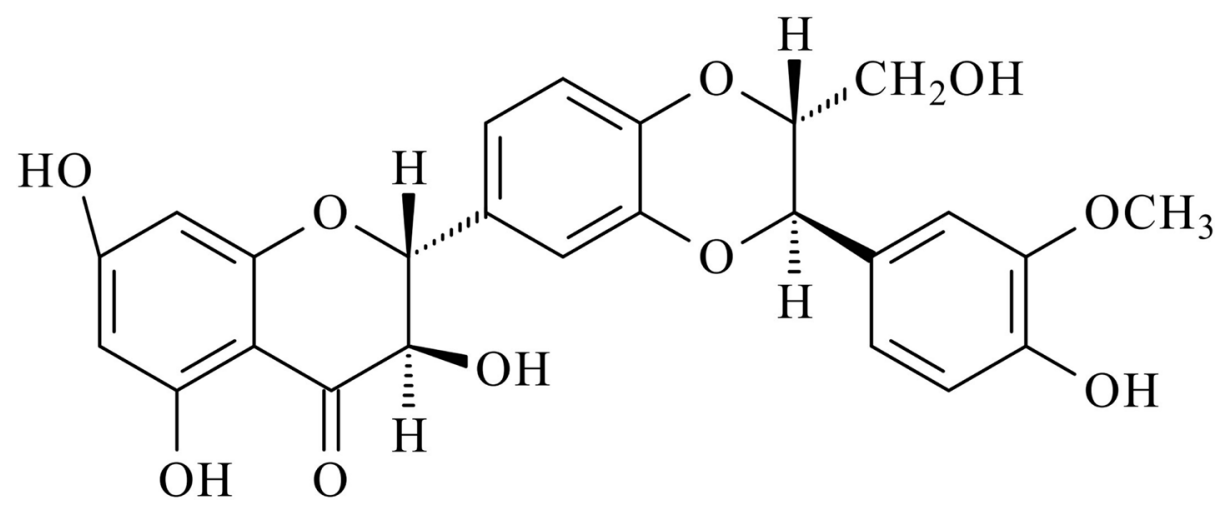

Figure 1: Chemical structures of silibinin. 
myeloblastic leukemia cells [19, 20]. A study suggested that silibinin could induce differentiation as a single agent and increase the levels of several differentiation-related transcription factors (TFs), such as members of jun and CCAAT-enhancer-binding protein (C/EBP) families, which may facilitate association of signal transduction factors during cellular differentiation [21]. Furthermore, silibinin initiated and enhanced 1,25D induced differentiation of AML cells ex vivo and induced differentiation more efficiently when cooperated with $1,25 \mathrm{D}$ than with nonmodified 1,25D [21]. A further study suggested that inhibition of Cot1 by 4-(3-chloro-4-fluorophenylamino)-6(pyridin-3-yl-methylamino-3-cyano-[1-7]-naphthyridine) or Cot1 siRNA reduced ERK5 activity. This repression will then allow silibinin to increase the differentiation-promoting factors and cell cycle regulators, such as p27/kinase inhibition protein 1 (p27Kip1), which leads to cell cycle arrest, induced by 1,25D in AML cells [22]. Hughes et al. have further shown that silibinin potentiates 1,25D-induced differentiation and growth arrest in AML Cells [18]. This anti-AML effect was related, in part, to upregulation of vitamin $\mathrm{D}$ receptor (VDR) and retinoid $\mathrm{X}$ receptor $(\mathrm{RXR} \alpha)$ levels compatible with increasing transactivation of the vitamin $\mathrm{D}$ response element (VDRE). What is more, silibinin activates the Nrf2/Antioxidant Response Element (Nrf2/ ARE) signaling pathway, an upstream positive regulator of VDR and RXR $\alpha$ [17]. Cytosine arabinoside (Ara-C) is widely used in the treatment of AML in humans but often becomes ineffective because of increasing resistance to the drug. It is noteworthy that Ara-C in combination with silibinin showed synergistic potential and decreased the IC50 value of Ara-C in-vitro. Thus combined treatment is a better strategy with a reduced cytotoxicity profile [23]. However, further study in vivo is needed to be carried out to establish the feasibility of this combined therapy in a larger population to firmly determine potency and the underlying mechanism of action. Although silibinin has been demonstrated to exert an anti-cancer effect, more studies are needed in future to establish the relative importance of these signaling molecules in silibinininduced inhibition of AML cells.

\section{Anaplastic large cell lymphoma}

Anaplastic large cell lymphoma (ALCL) is a distinct subset of T-cell non-Hodgkin lymphomas (NHL). Primary systemic ALCL mostly occurred in childhood, about $40 \%$ of NHL cases diagnosed in the pediatric patient are primary systemic ALCL, whereas it just accounts for $<5 \%$ of NHL in adults [24, 25]. Nucleophosmin-anaplastic lymphoma kinase (NPM-ALK), an oncogenic fusion protein, has been demonstrated to central the pathogenesis of ALK-positive ALCL (ALK+ALCL) [26]. NPM-ALK is regarded to mediate tumorigenesis via series of cellular pathways, such as phosphatidylinositol 3-kinase (PI3K)/ Akt, janus kinase/ signal transducer and activator of transcription 3 (Jak/STAT3), Jun N-terminal kinase (JNK) and MEK/extracellular regulated protein kinase (ERK). All of these pathways can promote cell proliferation, survival, and migration [27-30]. Recently, Molavi et al. have found that the phosphorylation/activation of NPMALK and its critical substrates or downstream mediators, such as STAT3, MEK/ERK, and Akt, were efficiently suppressed by silibinin in ALK+ALCL cells. Also, silibinin inhibited the expression of B-cell lymphoma-2 (Bcl-2), survivin and JunB, which were pathogenetic important in ALK + ALCL and upregulated by NPM-ALK. Silibinin sensitized SRY (sex determining region Y)-box 2 (Sox2), a master transcriptional factor, was shown to be important in maintaining the pluripotency of embryonic stem cells and active ALK+ALCL cells exposed to a widely used chemotherapeutic drug, doxorubicin, in ALCL $[31,32]$. Crizotinib, a small molecule competitive inhibitor of anaplastic lymphoma kinase (ALK), has also shown high cytoreductive antitumour activity in anaplastic large-cell lymphoma [33, 34]. Interestingly, it has been observed that, in crizotinib-resistant cells in ALK-rearranged lung cancer, silibinin-induced inhibition of STAT3 worked together with crizotinib to overcome resistance and restore sensitivity [35]. A few studies, however, have reported the anticancer effect of silibinin in ALCL, and thus could be a potential drug for novel ALCL therapy. More research is needed to elucidate further the functional mechanisms of silibinin in ALCL and explore more of its biological prospects for use in treatment.

\section{Multiple myeloma}

Multiple myelomas (MM), a monoclonal tumor of plasma cells, is the second most frequent and age-adjusted hematological malignancy. The incidence of $\mathrm{MM}$ is 100,000 per year in the USA and Europe [36]. MM cells were characterized by extensive somatic hypermutation of immunoglobulin genes, high bone marrow dependence, and absence of IgM expression. So far, the treatments of $\mathrm{MM}$ are primarily chemotherapies in conjunction with proteasome inhibitors (PIs), bone marrow (BM) transplantation, and antiresorptive agents such as bisphosphonates corticosteroids. Silibinin has, however, been demonstrated to exert anti-multiple myeloma efficacy. Silibinin inhibition of cellular proliferation and increased apoptosis via repression of PI3K/Akt(mammalian target of rapamycin) mTOR signaling have been recently reported to occur in U266 MM cells [37].

\section{CONCLUSIONS}

In this report, we have reviewed the potential of silibinin to potently suppress the hematological disorders, such as $\beta$-TM, AML, ALCL, and MM. However, the mechanisms of its effect in displaying these therapeutic properties are not entirely clear; taken together, the evidence from a series of studies showed that silibinin 
exhibits anti-hematological disorders effects via inhibiting oxidative stress or inducing differentiation and growth arrest in these disease model cell lines (Figure 2). It is well known that iron overload and oxidative stress are the main reasons for immune deficiency in the $\beta$-TM major, which was related to the prognosis of $\beta$-TM $[4,5]$. It is noteworthy that, a series of studies showed that silibinin exerts iron-chelating property and restores immune response defects in patients with $\beta$-TM major [9-11]. Further study demonstrated that silibinin function mainly via a direct action on cytokine-producing mononuclear cells and reducing ferritin and free radical generation to mediated immune response in $\beta$-TM [3]. As for AML cells, silibinin was capable of markedly suppressing their growth by producing an antiproliferative effect, leading to a massive apoptotic cell death [16]. Further studies have clarified that this anti-AML effect based on the by-pass of the block to differentiation caused by mutations and/ or epigenetic change in AML cells. Additionally, silibinin increases the levels of TFs, such as members of jun and $\mathrm{C} / \mathrm{EBP}$ families [21] and also has been demonstrated to enhance $1,25 \mathrm{D}$ differentiation inducing capability potential for differentiation-induced AML treatment [18-21]. Further studies have suggested that inhibition of Cot1 by Cot1 inhibitor, such as Cot1 siRNA, could induce ERK5 activity and subsequently allowed silibinin to increase $\mathrm{p} 27 \mathrm{Kip} 1$, which then leads to cell cycle arrest, promoted by 1,25D in AML cells [22]. Nrf2 is persistently activated in AML. Study showed that 1-(4-(tert-Butyl) benzyl)-3-(4-chlorophenyl)-N-hydroxy-1H pyrazole-5carboxamide (4f), inhibition of Nrf2 , induced apoptosis, at least in part, of human AML cells via Nrf2 signaling [38]. Similarily, it was showed that silibinin might potentiate 1,25D-induced differentiation and growth arrest in AML cells via activation of the Nrf2/ARE signaling pathway, and subsequently upregulate VDR and RXR $\alpha$ levels [17]. A combination of Ara-C and silibinin has been reported to exhibit synergistic potential and decreased the IC50 value of Ara-C in-vitro. The underlying mechanism, however, is not well defined [23]. In ALK+ALCL cells, studies showed that silibinin could efficiently suppress the activation of NPM-ALK and its key downstream mediators, such as STAT3, MEK/ERK, and Akt. Besides, it inhibited the expression of Bcl-2, survivin and JunB and upregulation by NPM-ALK. Silibinin could also sensitize Sox2, which is the unique target signaling pathway of silibinin in ALCL, active ALK+ALCL cells to doxorubicin $[31,32]$. What's more, further study showed that Silybum marianum was associated with a trend towards significant reductions in liver toxicity in children with ALL with liver toxicity [39]. In MM cells, silibinin has been demonstrated to be useful in the treatment of MM via inhibition of

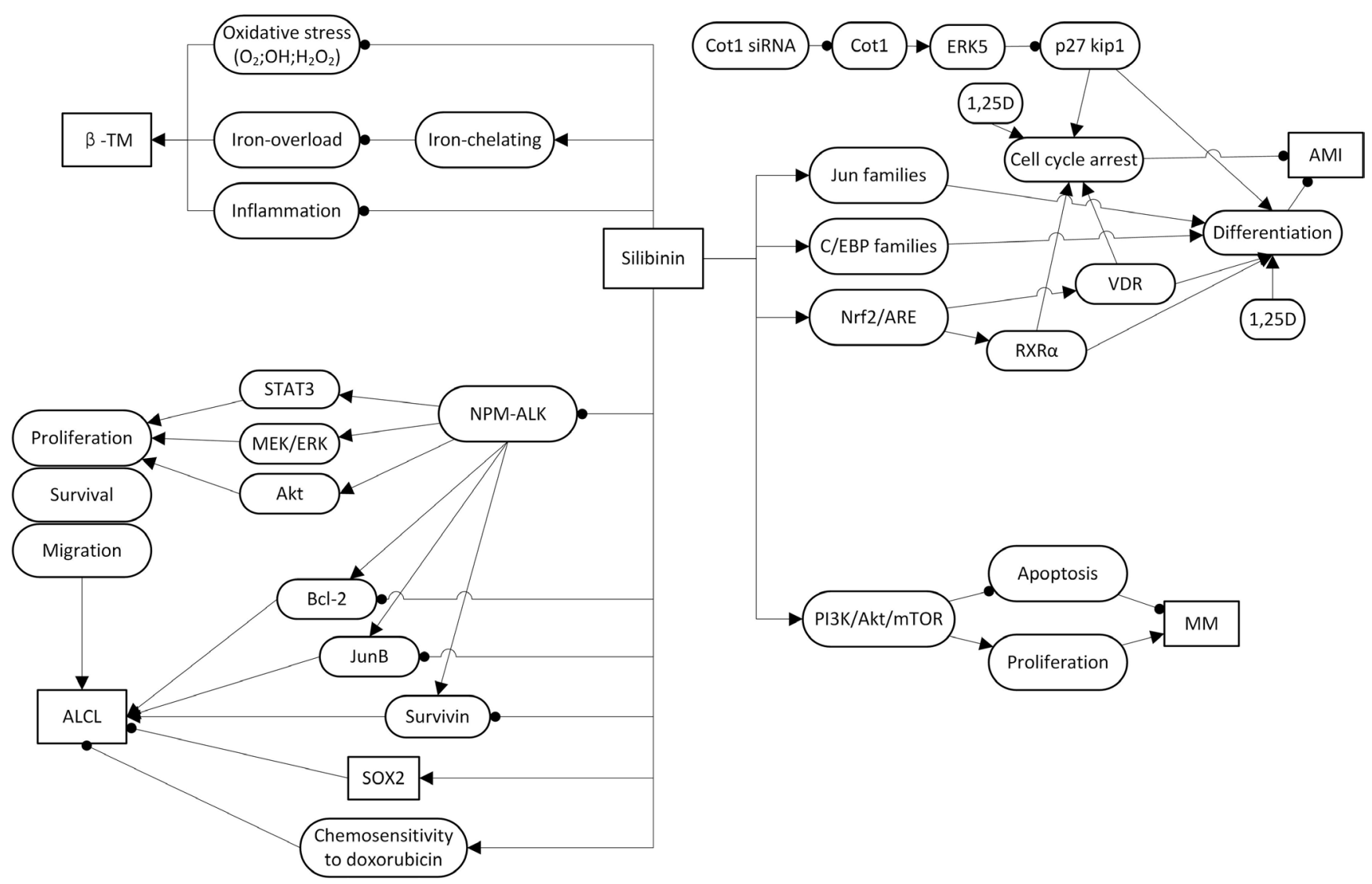

Figure 2: Signaling pathways and the role of silibinin in $\beta$-thalassemia; acute myeloid leukemia; Anaplastic large cell lymphoma and multiple myelomas. 
Table 1: Description of different type of hematological disorders

\begin{tabular}{|c|c|c|c|c|}
\hline $\begin{array}{l}\text { Hematological } \\
\text { disorder }\end{array}$ & Year & $\begin{array}{l}\text { Experimental } \\
\text { subject }\end{array}$ & Mechanism of action & Literatures \\
\hline \multirow{5}{*}{$\beta$-TM } & 2009 & human & iron-chelating and reducing iron overload & Gharagozloo et al. [9] \\
\hline & 2013 & human & iron-chelating and reducing iron overload & Moayedi et al. [10] \\
\hline & 2013 & human & iron-chelating and reducing iron overload & Hagag et al. [12] \\
\hline & 2014 & human & inhibiting IL-10 and increasing TGF-b and IL-23 & Balouchi et al. [11] \\
\hline & 2013 & human & stimulating cell-mediated immune response & Gharagozloo et al. [3] \\
\hline \multirow{4}{*}{ AML } & 2010 & $\begin{array}{l}\text { human AML } \\
\text { cells }\end{array}$ & $\begin{array}{l}\text { suppressing cell growth and produced an anti- } \\
\text { proliferative effect }\end{array}$ & Pesakhov et al. [16] \\
\hline & 2001 & HL-60 Cells & enhancing protein kinase $\mathrm{C}(\mathrm{PKC})$ activity & Kang et al. [19] \\
\hline & 2010 & human & increasing jun and $\mathrm{C} / \mathrm{EBP}$ families & Pesakhov et al. [21] \\
\hline & 2012 & HL-60 Cells & activating the Nrf2/ARE)signaling pathway & Wassermann et al. [17] \\
\hline ALCL & 2016 & $\begin{array}{l}\mathrm{ALK}^{+} \mathrm{ALCL} \\
\text { cells }\end{array}$ & $\begin{array}{l}\text { 1.activating of NPM-ALK and suppressing its } \\
\text { critical substrates or downstream mediators, such } \\
\text { as STAT3, MEK/ERK, and Akt } \\
\text { 2. inhibiting the expression of Bcl-2, survivin and } \\
\text { JunB } \\
\text { 3. sensitizing Sox2 }\end{array}$ & Molavi et al. [32] \\
\hline MM & 2016 & $\begin{array}{l}\mathrm{U} 266 \mathrm{MM} \\
\text { cells }\end{array}$ & inhibiting PI3K/Akt- mTOR signaling & Feng et al. [37] \\
\hline
\end{tabular}

proliferation and an increase in apoptosis via inhibiting PI3K/Akt-mTOR signaling pathways [37]. These are emerging new ways of silibinin usage which may be promising therapeutic interventions for the treatment of $\beta$-TM, AML, ALCL, and MM. There are, however, only a hand full of studies that reflect the use of the drug in an anticancer therapy of ALCL, and MM. Thus more research is needed to enlighten the relevant mechanisms of silibinin action in the treatment of the latter.

\section{EXPERT OPINION}

In this report, we have discussed silibinin in hematological disorders, such as $\beta$-TM, AML, ALCL, and $\mathrm{MM}$, considering silibinin as promising therapeutic intervention, based on the studies in the last five years. To this day, a series of studies on the mechanisms of action of silibinin have been carried out, and several experts have highlighted on its potential involvement in the repair of the aberrance in the interaction between signaling pathways, described in (Figure 2 and Table 1) and $\beta$-TM, AML, ALCL and MM therapy. We have discovered interesting viewpoints, based on these investigations a) the functional mechanisms of silibinin in AML cells, whether it is through Nrf2/ARE/VDR, Nrf2/ARE/RXR $\alpha$, jun families or $\mathrm{C} / \mathrm{EBP}$ families is to eventually regulate cell differentiation to exert an anti-cancer effect [21] [17]. We hypothesized that new signaling pathways by which silibinin regulate cell differentiation in AML cells would be elucidated soon, which will contribute to the effectiveness of silibinin anti-cancer effect to ensure a better understanding; b) a combined treatment strategy may be a good approach. For example, silibinin in combination with $1,25 \mathrm{D}$ can obviously potentiate 1,25D-induced differentiation and growth arrest in AML Cells [17]. The combination of Ara-C and silibinin can decrease the IC50 value of Ara-C in AML cells [23]. What's more, silibinin can increase the chemosensitivity of ALK+ALCL cells to doxorubicin [32]. The inference is that silibinin in combination with doxorubicin would exert a better therapeutic effect than doxorubicin alone. c) It has also been reported that silibinin can inhibit pSTAT3 activation in preclinical cancer models, especially in solid tumors [40]. We also find that, in hematological disorders, silibinin also can suppress the activation of some pathways, such as NPM-ALK, and then suppress its key downstream pSTAT3 [28]. It is noteworthy that, silibinin still have some limitation of clinical use: One of the biggest limitations in humans is its low oral bioavailability [41]. This forces us to seek new formulations. Luckily, recently, interesting clinical antitumor activity has been reported with a new formulation (Eurosil85 - Legasil(R)) in solid cancer patients. We expect that new formulation in this scenario would consider this point to increase oral bioavailability. Although an increasing number of studies explore the role of silibinin in hematological disorders therapy, there are still need extend laboratory studies to help dissect the signaling pathways involved and identify the effect of silibinin in these disorders. For example, in MM, much more cell lines should be presented to represent the whole, genetic, spectrum of patient's characteristics. In addition, co-cultures with stromal cells 
may be helpful to mimic the tumour microenvironment and predict effects on drug sensitivity. What's more, further animal experiments and further clinical studies are need to identify the microenvironment of tumour cells growth, drug resistance, combined drugs, when to be used, primary treatment and the therapeutic effect in relapsed patients of silibinin in hematological disorders therapy.

\section{Five-year view}

Over the next 5 years, we expect the potential effect of therapy of silibinin in hematological disorders. Pharmacological evidence and clinical trial results support the interpretation that silibinin treats hematological disorders by regulating potential signaling pathways, such as $\mathrm{Nrf}$ / ARE/VDR signaling, Nrf2/ARE/RXR $\alpha$ signaling, PI3K/ Akt/mTOR signaling and NPM-ALK associated signaling. We predict that extend laboratory studies and further clinical studies will be done to help identify the extend pathogenetic mechanism and the therapeutic effect, usage and safety of silibinin in different hematological disorders. We further predict that silibinin may be approved for the treatment of these hematological disorders in the near future.

\section{Key issues}

- Silibinin, a non-toxic natural compound, may be useful in the treatment of hematological disorders, such as $\beta$-TM, AML, ALCL, MM by inducing growth inhibition.

- The treatment strategy of silibinin in combination with some other hemic and lymphatic disease therapeutic drugs for hemic and lymphatic may enhance the therapeutic effects of these drugs

- There are multiple preclinical data supporting activity of silibinin in vitro and in vivo in patients with $\beta$-TM, AML, ALCL, MM, but there are not sufficient published clinical data of efficacious and safety of silibinin treatment in human patients with $\beta$-TM, AML, ALCL, MM, especially in ALCL and MM.

\section{Abbreviations}

AKT: protein kinase $\mathrm{B}(\mathrm{PKB})$; ALCL: anaplastic large cell lymphoma; AML: acute myeloid leukemia; BCL2: B-cell lymphoma-2; C/EBP :CCAAT-enhancer-binding protein; Erk5:extracellular regulated protein kinases 5; MEK/ERK:MEK/extracellular regulated protein kinase; MM: multiple myeloma; Nrf2/ARE :Nrf2/antioxidant response element; NPM-ALK: nucleophosmin-anaplastic lymphoma kinase; p27Kip1:p27/kinase inhibition protein 1;PI3K/Akt/mTOR: phosphatidylinositol 3-kinase/ protein kinase $\mathrm{B} /$ mammalian target of rapamycin; $\mathrm{RXR} \alpha$ : retinoid $\mathrm{X}$ receptor; STAT3: signal transducer and activator of transcription 3;SOX2: SRY (sex determining region $\mathrm{Y}$ )box 2; VDR: vitamin D receptor; $\beta$-TM: $\beta$-thalassemia; 1,25D:1,25-dihydroxyvitamin D3.

\section{ACKNOWLEDGMENTS}

There was no financial support or funding for this review.

\section{CONFLICTS OF INTEREST}

The authors report no declarations of interest.

\section{REFERENCES}

1. Zhu XX, Ding YH, Wu Y, Qian LY, Zou H, He Q. Silibinin: a potential old drug for cancer therapy. Expert Rev Clin Pharmacol. 2016; 1-8.

2. Forghani $\mathrm{P}$, Khorramizadeh MR, Waller EK. Silibinin inhibits accumulation of myeloid-derived suppressor cells and tumor growth of murine breast cancer. Cancer Med. $2014 ; 3: 215-24$.

3. Gharagozloo M, Karimi M, Amirghofran Z. Immunomodulatory effects of silymarin in patients with betathalassemia major. Int Immunopharmacol. 2013; 16:243-7.

4. Kushner JP, Porter JP, Olivieri NF. Secondary iron overload. Hematology Am Soc Hematol Educ Program. 2001; 47-61.

5. Cunningham-Rundles S, Giardina PJ, Grady RW, Califano C, McKenzie P, De Sousa M. Effect of transfusional iron overload on immune response. J Infect Dis. 2000; 182:S115-21.

6. Abdalla MY, Fawzi M, Al-Maloul SR, El-Banna N, Tayyem RF, Ahmad IM. Increased oxidative stress and iron overload in Jordanian beta-thalassemic children. Hemoglobin. 2011; 35:67-79.

7. Rashidi M, Aboomardani M, Rafraf M, Arefhosseini SR, Keshtkar A, Joshaghani H. Effects of Vitamin E and Zinc Supplementation on Antioxidants in Beta thalassemia major Patients. Iran J Pediatr. 2011; 21:8-14.

8. Ghone RA, Kumbar KM, Suryakar AN, Katkam RV, Joshi NG. Oxidative stress and disturbance in antioxidant balance in beta thalassemia major. Indian J Clin Biochem. 2008; 23:337-40.

9. Gharagozloo M, Moayedi B, Zakerinia M, Hamidi M, Karimi M, Maracy M, Amirghofran Z. Combined therapy of silymarin and desferrioxamine in patients with betathalassemia major: a randomized double-blind clinical trial. Fundam Clin Pharmacol. 2009; 23:359-65.

10. Moayedi B, Gharagozloo M, Esmaeil N, Maracy MR, Hoorfar H, Jalaeikar M. A randomized double-blind, placebo-controlled study of therapeutic effects of silymarin in beta-thalassemia major patients receiving desferrioxamine. Eur J Haematol. 2013; 90:202-9.

11. Balouchi S, Gharagozloo M, Esmaeil N, Mirmoghtadaei M, Moayedi B. Serum levels of TGFbeta, IL-10, IL-17, and IL23 cytokines in beta-thalassemia major patients: the impact of silymarin therapy. Immunopharmacol Immunotoxicol. $2014 ; 36: 271-4$. 
12. Hagag AA, Elfrargy MS, Gazar RA, El-Lateef AE. Therapeutic value of combined therapy with deferasirox and silymarin on iron overload in children with Beta thalassemia. Mediterr J Hematol Infect Dis. 2013; 5:e2013065.

13. Lowenberg B, Downing JR, Burnett A. Acute myeloid leukemia. N Engl J Med. 1999; 341:1051-62.

14. Siegel RL, Fedewa SA, Miller KD, Goding-Sauer A, Pinheiro PS, Martinez-Tyson D, Jemal A. Cancer statistics for Hispanics/Latinos, 2015. CA Cancer J Clin. 2015; 65:457-80.

15. De Kouchkovsky I, Abdul-Hay M. 'Acute myeloid leukemia: a comprehensive review and 2016 update'. Blood Cancer J. 2016; 6:e441.

16. Pesakhov S, Khanin M, Studzinski GP, Danilenko M. Distinct combinatorial effects of the plant polyphenols curcumin, carnosic acid, and silibinin on proliferation and apoptosis in acute myeloid leukemia cells. Nutr Cancer. 2010; 62:811-24.

17. Wassermann R, Novik V, Danilenko M. Cell-Type-Specific Effects of Silibinin on Vitamin D-Induced Differentiation of Acute Myeloid Leukemia Cells Are Associated with Differential Modulation of RXRalpha Levels. Leuk Res Treatment. 2012; 2012:401784.

18. Hughes PJ, Marcinkowska E, Gocek E, Studzinski GP, Brown G. Vitamin D3-driven signals for myeloid cell differentiation-implications for differentiation therapy. Leuk Res. 2010; 34:553-65.

19. Kang SN, Lee MH, Kim KM, Cho D, Kim TS. Induction of human promyelocytic leukemia HL-60 cell differentiation into monocytes by silibinin: involvement of protein kinase C. Biochem Pharmacol. 2001; 61:1487-95.

20. Wang Q, Salman H, Danilenko M, Studzinski GP. Cooperation between antioxidants and 1,25-dihydroxyvitamin D3 in induction of leukemia HL60 cell differentiation through the JNK/AP-1/Egr-1 pathway. J Cell Physiol. 2005; 204:964-74.

21. Zhang J, Harrison JS, Uskokovic M, Danilenko M, Studzinski GP. Silibinin can induce differentiation as well as enhance vitamin D3-induced differentiation of human AML cells ex vivo and regulates the levels of differentiation-related transcription factors. Hematol Oncol. 2010; 28:124-32.

22. Wang X, Gocek E, Novik V, Harrison JS, Danilenko M, Studzinski GP. Inhibition of Cot1/Tlp2 oncogene in AML cells reduces ERK5 activation and up-regulates p27Kip1 concomitant with enhancement of differentiation and cell cycle arrest induced by silibinin and 1,25-dihydroxyvitamin D(3). Cell Cycle. 2010; 9:4542-51.

23. Desai UN, Shah KP, Mirza SH, Panchal DK, Parikh SK, Rawal RM. Enhancement of the cytotoxic effects of Cytarabine in synergism with Hesperidine and Silibinin in Acute Myeloid Leukemia: An in-vitro approach. J Cancer Res Ther. 2015; 11:352-7.

24. Sandlund JT, Pui CH, Santana VM, Mahmoud H, Roberts WM, Morris S, Raimondi S, Ribeiro R, Crist WM, Lin JS. Clinical features and treatment outcome for children with CD30+ large-cell non-Hodgkin's lymphoma. J Clin Oncol. 1994; 12:895-8.

25. Kadin ME, Morris SW. The $\mathrm{t}(2 ; 5)$ in human lymphomas. Leuk Lymphoma. 1998; 29:249-56.

26. Amin HM, Lai R. Pathobiology of ALK+ anaplastic largecell lymphoma. Blood. 2007; 110:2259-67.

27. Kawauchi K, Ogasawara T, Yasuyama M, Otsuka K, Yamada O. The PI3K/Akt pathway as a target in the treatment of hematologic malignancies. Anticancer Agents Med Chem. 2009; 9:550-9.

28. Al Zaid Siddiquee K, Turkson J. STAT3 as a target for inducing apoptosis in solid and hematological tumors. Cell Res. 2008; 18:254-67.

29. Platanias LC. Map kinase signaling pathways and hematologic malignancies. Blood. 2003; 101:4667-79.

30. Staber PB, Vesely P, Haq N, Ott RG, Funato K, Bambach I, Fuchs C, Schauer S, Linkesch W, Hrzenjak A, Dirks WG, Sexl V, Bergler H, et al. The oncoprotein NPM-ALK of anaplastic large-cell lymphoma induces JUNB transcription via ERK1/2 and JunB translation via mTOR signaling. Blood. 2007; 110:3374-83.

31. Gelebart P, Hegazy SA, Wang P, Bone KM, Anand M, Sharon D, Hitt M, Pearson JD, Ingham RJ, Ma Y, Lai R. Aberrant expression and biological significance of Sox2, an embryonic stem cell transcriptional factor, in ALK-positive anaplastic large cell lymphoma. Blood Cancer J. 2012; 2:e82.

32. Molavi O, Samadi N, Wu C, Lavasanifar A, Lai R. Silibinin suppresses NPM-ALK, potently induces apoptosis and enhances chemosensitivity in ALK-positive anaplastic large cell lymphoma. Leuk Lymphoma. 2016; 57:1154-62.

33. Christensen JG, Zou HY, Arango ME, Li Q, Lee JH, McDonnell SR, Yamazaki S, Alton GR, Mroczkowski B, Los G. Cytoreductive antitumor activity of PF-2341066, a novel inhibitor of anaplastic lymphoma kinase and c-Met, in experimental models of anaplastic large-cell lymphoma. Mol Cancer Ther. 2007; 6:3314-22.

34. Mahuad CV, Reparaz Mde L, Zerga ME, Aizpurua MF, Casali C, Garate G. Three Years Sustained Complete Remission Achieved in a Primary Refractory ALK-Positive Anaplastic T Large Cell Lymphoma Treated with Crizotinib. Rare Tumors. 2016; 8:6266.

35. Cuyas E, Perez-Sanchez A, Micol V, Menendez JA, Bosch-Barrera J. STAT3-targeted treatment with silibinin overcomes the acquired resistance to crizotinib in ALKrearranged lung cancer. Cell Cycle. 2016; 15:3413-3418.

36. Rollig C, Knop S, Bornhauser M. Multiple myeloma. Lancet. 2015; 385:2197-208.

37. Feng N, Luo J, Guo X. Silybin suppresses cell proliferation and induces apoptosis of multiple myeloma cells via the PI3K/Akt/ mTOR signaling pathway. Mol Med Rep. 2016; 13:3243-8.

38. Zhang J, Su L, Ye Q, Zhang S, Kung H, Jiang F, Jiang G, Miao J, Zhao B. Discovery of a novel Nrf2 inhibitor that induces apoptosis of human acute myeloid leukemia cells. Oncotarget. 2017; 8:7625-7636. https://doi.org/10.18632/ oncotarget.13825. 
39. Ladas EJ, Kroll DJ, Oberlies NH, Cheng B, Ndao DH, Rheingold SR, Kelly KM. A randomized, controlled, double-blind, pilot study of milk thistle for the treatment of hepatotoxicity in childhood acute lymphoblastic leukemia (ALL). Cancer. 2010; 116:506-13.

40. Bosch-Barrera J, Menendez JA. Silibinin and STAT3: A natural way of targeting transcription factors for cancer therapy. Cancer Treat Rev. 2015; 41:540-6.
41. Bosch-Barrera J, Sais E, Canete N, Marruecos J, Cuyas E, Izquierdo A, Porta R, Haro M, Brunet J, Pedraza S, Menendez JA. Response of brain metastasis from lung cancer patients to an oral nutraceutical product containing silibinin. Oncotarget. 2016; 7:32006-14. https://doi. org/10.18632/oncotarget. 7900 . 